\section{Clonal Propagation In Vitro of Paphiopedilum Hybrids from Adult Plants}

\author{
Vi Nguyen Tuong Do \\ Ph.D. Program of Agriculture Science, National Chiayi University, 60004 \\ Chiayi, Taiwan, ROC
}

\author{
Shan-Te Hsu \\ Department of Horticulture, National Chiayi University, 60004 Chiayi, \\ Taiwan, ROC
}

\section{Yung-I Lee}

Biology Department, National Museum of Natural Science, 40453 Taichung, Taiwan, ROC; and Department of Life Sciences, National Chung Hsing University, 40227 Taichung, Taiwan, ROC

Additional index words. apical dominance, axillary bud, micropropagation, shoot, multiplication

\begin{abstract}
The aim of this study was to develop an efficient protocol for shoot tip culture from adult plants of Paphiopedilum Pfitzer. A considerable seasonal effect on explant collection was observed in the aseptic cultures established from adult plants, including the survival and microbial contamination of explants. The shoot tip explants excised from adult plants in February and May showed higher survival and had less contamination than those explants excised in August and November. Moreover, the season of explant collection also affected the subsequent shoot forming capacity and multiplication of axillary buds. In Paphiopedilum 'In-Charm Silver Bell', higher shoot forming capacity was observed in February and May, whereas higher shoot multiplication was observed only in February. In Paphiopedilum 'Hsinying Maudiae Leopard', both February and May were optimal timing for shoot forming capacity and multiplication. We also demonstrated the effectiveness of transcinnamic acid (tCA), an antiauxin chemical in diminishing the apical dominance of shoot tip explant and thus improving the axillary bud outgrowth. In $P$. 'In-Charm Silver Bell', the addition of $100 \mu M$ tCA plus $13.3 \mu M$ 6-benzylaminopurine (BA) for 1 month promoted axillary shoot bud formation from shoot tip explants as compared with the control.
\end{abstract}

Paphiopedilum is commonly known as slipper orchid because of the likeness of the pouch-shaped lip to a lady's slipper. It is a terrestrial orchid, containing $\approx 80$ species that are native to habitats ranging from the Himalayas to southwestern China and southeast Asia (Cribb, 1998). Paphiopedilum is one of the most popular orchids that has been cultivated for more than 100 years, and a wide range of attractive hybrids and cultivars has been produced as potted plants or cut flowers in horticultural markets (Miguel et al., 2010). Micropropagation of Paphiopedilum is known to be intricate through tissue culture techniques (Arditti and Ernst, 1993; Stewart and Button, 1975), and for this reason the selected elites are usually propagated by vegetative

Received for publication 4 Dec. 2018. Accepted for publication 20 Feb. 2019.

This work was supported by grant 106AS-8.6.3-FD-Z1 from the Council of Agriculture, Executive Yuan, ROC, to Shan-Te Hsu.

S.-T.H. and Y.-I.L. are the corresponding authors. E-mail: hsust@mail.ncyu.edu.tw or leeyungi@ hotmail.com. division (Lee, 2018). Therefore, a rapid, reliable protocol for propagation is required for massive propagation of the selected elites.

Attempts to establish shoot tip culture in Paphiopedilum adult plants indicated that the major problems encountered are 1) getting aseptic explants from mature plants through the procedure of surface sterilization is difficult; and 2) explants from mature plants are obstinate to multiply or regenerate in vitro (Arditti and Ernst, 1993; Chugh et al., 2009). Plant regeneration and shoot multiplication through seed-derived explants in vitro has been reported in a number of Paphiopedilum species and hybrids (Chen et al., 2004; Hong et al., 2008; Huang et al., 2001; Lin et al., 2000; Long et al., 2010; $\mathrm{Ng}$ et al., 2010; Ng and Saleh, 2011; Nhut et al., 2007; Udomdee et al., 2012); however, those seed-derived explants are not true-to-type and heterozygous.

Until now, only a few cases of in vitro clonal propagation using the explant collected from adult plants has been reported (Huang, 1988; Stewart and Button, 1975). Recently, Liao et al. (2011) reported the shoot induction and plant regeneration in Paphiopedilum using flower buds as explants. These results imply that the protocol of starting aseptic culture from adult plants still has considerable room for improvement. In woody plants, the initial success of an aseptic culture is directly related to the timing of explant collection from adult plants (Evers et al., 1988; Kartsonas and Papafotiou, 2007). The seasonal influence in explant collection may affect the endogenous physiological state of explants and the surrounding composition of microorganisms. In our previous study, the timing of explant collection was critical for the initial success of aseptic culture in Cypripedium L. (a relative genus to Paphiopedilum) adult plants (Lee, 2010). Cypripedium occurs in the temperate region, whereas Paphiopedilum is native to tropical and subtropical Asia. It is not certain if the seasonal influence of explant collection also plays a role in establishing the aseptic culture of Paphiopedilum. Therefore, the objectives of this study were to investigate the effect of timing of explant collection from adult plants on micropropagation, and to examine the effect of transcinnamic acid (tCA), a potent inhibitor of auxin efflux, on in vitro shoot multiplication of Paphiopedilum.

\section{Materials and Methods}

Plant material, the timing of explant collection, and culture condition. The mature plants of Paphiopedilum Maudiae-type hybrids (i.e., Paphiopedilum 'In-Charm Silver Bell' and Paphiopedilum 'Hsinying Maudiae Leopard') were maintained in a greenhouse at the Horticulture Technology Center, National Chiayi University, Chiayi, Taiwan. Plants were grown in pine bark medium (Orchiata; Besgrow, Christchurch, New Zealand) under $70 \%$ shade. To investigate the seasonal effect on explant survival and shoot multiplication, the young shoot bud of $5 \mathrm{~cm}$ in length was collected from adult plants in early of February, May, August, and November. The young shoot bud was first washed under running tap water for $15 \mathrm{~min}$, then immersed in $2 \%$ neutral liquid detergent Extran MA 02 (Sigma-Aldrich Co., St. Louis, $\mathrm{MO}$ ) for $30 \mathrm{~min}$. In a laminar airflow, the outer young leaves were removed from the shoot bud, and then the shoot buds was immersed in $1 \%$ sodium hypochlorite solution with $0.1 \%$ Tween 20 (Sigma-Aldrich Co.) for $18 \mathrm{~min}$. After three rinses with sterile distilled water, the shoot bud with one leaf attached was used as the explant (Figs. 1A and 2A). The culture medium used in this experiment was the modified Murashige and Skoog (MS) medium (Murashige and Skoog, 1962), which contained one-fourth strength macro-elements with full-strength microelements and supplemented with $2 \mathrm{mg} \cdot \mathrm{L}^{-1} \mathrm{gly}$ cine, $0.5 \mathrm{mg} \cdot \mathrm{L}^{-1}$ niacin, $0.5 \mathrm{mg} \cdot \mathrm{L}^{-1}$ pyridoxine $\mathrm{HCl}, 0.1 \mathrm{mg} \cdot \mathrm{L}^{-1}$ thiamine, $100 \mathrm{mg} \cdot \mathrm{L}^{-1}$ myoinositol, $20 \mathrm{~g} \cdot \mathrm{L}^{-1}$ sucrose (Sigma-Aldrich Co.), $4 \mathrm{~g} \cdot \mathrm{L}^{-1}$ agar (Becton, Dickinson and Co., Sparks, MD) and 2 g. $\mathrm{L}^{-1}$ Gelrite (SigmaAldrich Co.). The plant growth regulator consisted of $13.3 \mu \mathrm{M}$ 6-benzylaminopurine (BA; Sigma-Aldrich Co.), and the $\mathrm{pH}$ value was 


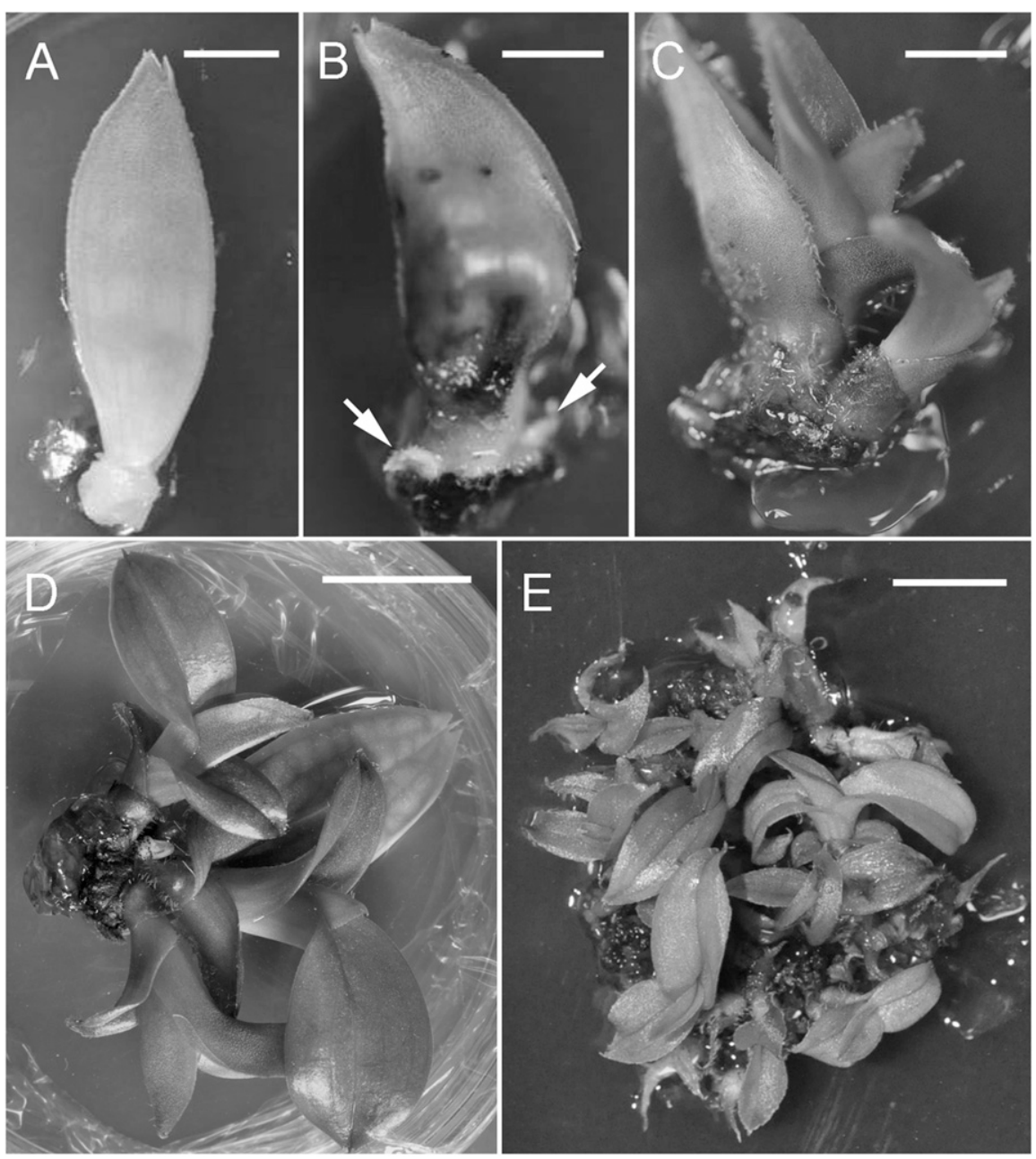

Fig. 1. Micropropagation of Paphiopedilum 'In-Charm Silver Bell'. (A) After surface sterilization, the lateral bud with one leaf attached was used as the explant. Bar $=1 \mathrm{~cm}$. (B) After 2 months of culture, the basal axillary buds (arrows) started to grow. Bar $=1 \mathrm{~cm}$. (C) After 5 months of culture, two axillary buds had arisen from the basal part of explants. Bar $=1 \mathrm{~cm}$. (D) The newly formed axillary shoots (as indicated in C) were excised for multiplication. After 3 months of subculture, three new shoots were visible. Bar $=1 \mathrm{~cm}$. (E) The newly formed axillary shoots (as indicated in D) were excised again for multiplication. After 3 months of subculture, more shoot multiplication can be observed. Bar $=1 \mathrm{~cm}$.

adjusted to 5.7 with $1 \mathrm{~N} \mathrm{HCl}$ before autoclaving at $121^{\circ} \mathrm{C}$ and $1.2 \mathrm{~kg} \cdot \mathrm{cm}^{-2}$ for $20 \mathrm{~min}$. The cultures were inoculated onto $12.5 \mathrm{~mL}$ solidified medium in petri dishes $(100 \mathrm{~mm} \times$ $15 \mathrm{~mm}$ ), and maintained at $26 \pm 2{ }^{\circ} \mathrm{C}$ under a 16/8-h photoperiod with daylight fluorescent lamps (20 W; China Electric Co., Taipei, Taiwan), at a light intensity of $30 \mu \mathrm{mol} \cdot \mathrm{m}^{-2} \cdot \mathrm{s}^{-1}$. The explants were subcultured every $30 \mathrm{~d}$ and the explant survival percentage, the shoot forming percentage, and the mean shoot number per explant were recorded at $150 \mathrm{~d}$ of culture. Explant survival percentage $=$ number of explant survival/number of explant cultured $x$ $100 \%$; shoot forming percentage $=$ number of explant survival with shoot formation/number of explant survival $\times 100 \%$.

Shoot multiplication procedure. After 5 months of culture, the formation of multiple shoots (more than $1 \mathrm{~cm}$ in length) from the initial explants were separated, and each single shoot was cut vertically into two explants and placed onto the same culture medium as described previously. The explants were subcultured every $30 \mathrm{~d}$. After 3 months of subculture, as the multiple shoots (more than $1 \mathrm{~cm}$ in length) formed, they were separated and cut vertically for shoot multiplication. After 9 months of subculture (i.e., 3 times of multiplication), the number of new shoots (above $0.2 \mathrm{~cm}$ ) produced from one initial explant were recorded.

Effects of $t C A$ on shoot multiplication. To investigate the effect of tCA (Sigma-Aldrich Co.), a potent inhibitor of auxin efflux on shoot multiplication, the axillary buds collected in November were inoculated onto the one-fourth MS medium, as described previously, and supplemented with $100 \mu \mathrm{M}$ tCA and $13.3 \mu \mathrm{M}$ BA for 1 month. The medium without tCA was used as control. The cultures were maintained at $26 \pm 2{ }^{\circ} \mathrm{C}$ under a 16/8-h photoperiod with daylight fluorescent lamps (20 W; China Electric Co.), at a light intensity of $30 \mu \mathrm{mol} \cdot \mathrm{m}^{-2} \cdot \mathrm{s}^{-1}$. After $8 \mathrm{months}$ of culture, the number of shoot formations was investigated. This experiment was done with three replicates, and one replicate contained 10 explants.

Rooting and acclimatization of in vitro plantlets. In the multiplication medium, shoots $\approx 2 \mathrm{~cm}$ in length were excised and cultured on the rooting medium supplemented with $2.5 \mathrm{~g} \cdot \mathrm{L}^{-1}$ Hyponex No.1 (6.5N-6P-19K; Hyponex Japan Corp., Osaka, Japan), $0.3 \mathrm{~g} \cdot \mathrm{L}^{-1}$ urea, $1 \mathrm{~g} \cdot \mathrm{L}^{-1}$ peptone, $20 \mathrm{~g} \cdot \mathrm{L}^{-1}$ sucrose, $60 \mathrm{~g} \cdot \mathrm{L}^{-1}$ potato homogenate, $25 \mathrm{~g} \cdot \mathrm{L}^{-1}$ banana homogenate, $0.1 \mathrm{~g} \cdot \mathrm{L}^{-1}$ myoinositol, $0.5 \mathrm{~g} \cdot \mathrm{L}^{-1}$ active charcoal and solidified with 4 g. $\mathrm{L}^{-1}$ agar (Becton, Dickinson and Co.). The ripe banana and potato were peeled and cut into $\approx 1 \mathrm{~cm}^{3}$ cubes, then boiled for $20 \mathrm{~min}$ with $500 \mathrm{~mL}$ of distilled water and homogenized with a kitchen blender. These homogenates were added to the culture medium before the adjustment of $\mathrm{pH}$ value. The $\mathrm{pH}$ value was adjusted to 5.7 before autoclaving at $121{ }^{\circ} \mathrm{C}$ and $1.2 \mathrm{~kg} \cdot \mathrm{cm}^{-2}$ for $20 \mathrm{~min}$. The cultures were inoculated onto $50 \mathrm{~mL}$ solidified medium in the Magenta GA-7 plant culture box and maintained at $26 \pm 2{ }^{\circ} \mathrm{C}$ under a 16/8-h photoperiod with daylight fluorescent lamps at a light intensity of $30 \mu \mathrm{mol} \cdot \mathrm{m}^{-2} \cdot \mathrm{s}^{-1}$. After $4 \mathrm{months}$ of culture, the plantlets were $\approx 3$ to $4 \mathrm{~cm}$ in height with three leaves and two roots that were ready for acclimatization in the greenhouse, then taking out of flasks for planting.

Experimental design and statistical analysis. All experiments were performed in a completely randomized design and repeated three times. In these experiments, twelve replicates (plates) were used for each treatment, with one explant planted in each plate. Data were statistically analyzed using analysis of variance in combination with Fisher's protected least significant difference test at $P<0.05$. All statistical analysis was completed with SAS (version 9.0; Cary, NC).

\section{Results and Discussion}

Seasonal effects on establishment of initial aseptic culture. After 2 months of culture, the shoot tip became swollen and the basal axillary buds started growing (Figs. 1B and 2B). The season of explant collection for the establishment of initial aseptic culture is critical in Paphiopedilum micropropagation. Of the two hybrids tested, the survival percentage of explants was higher in February and May as compared with those in August and November; and the contamination percentage of explants was reduced in February and May as compared with those in August and November. For the browning of explants in this study, there was no significant difference between seasons (Table 1). These results indicate that microbial contamination is the main cause contributing to the lower survival of explants in August and November. It has been reported that the challenge of starting aseptic culture in Paphiopedilum is the great difficulty of removing microbial contamination from explants collected from cultivated plants in greenhouses (Huang, 1988). Although reducing the explant size could 
lessen the ratio of microbial contamination, reducing the explant size also diminishes the survival of explants in the initial aseptic culture. In this study, we found the optimum timing for explant collection in February and May without reducing the explant size. The different contamination of explants could be attributed to seasonal fluctuations of microbial population and activity (Martini et al., 2013).

Seasonal effects on shoot formation and multiplication. After 5 months of culture, a number of axillary buds arisen from the basal part of explants were visible (Figs. 1C and 2C). Of the two hybrids tested, the shoot forming capacity of explants was higher in February and May as compared with those in August and November (Table 2). The newly formed axillary shoots (above $1 \mathrm{~cm}$ ) were excised and further subcultured on the same fresh medium. After 3 months of subculture, multiple shoots were induced (Figs. 1D and 2D). The axillary shoots were excised and subcultured again. After another 3 months of subculture, the increased shoot multiplication rate was evident (Figs. 1E and 2E). For the shoot multiplication, explants of Paphiopedilum 'Hsinying Maudiae Leopard' produced more shoots in February and May as compared with those in August and November (Table 3). In Paphiopedilum 'In-Charm Silver Bell', the number of shoots formed per explant was reduced in May, as compared with those in February, and reached the lowest level in August and November. In studies with woody plants, the season of explant collection from adult plants is important on the initial aseptic culture and shoot multiplication (Kartsonas and Papafotiou, 2007; Kumar et al., 2005; Hohtola, 1988; Martini et al., 2013; Thomas and Ravindra, 1997). Such seasonal variation also has been observed previously for explants excised from adult plants of temperate orchids, such as Cypripedium formosanum Hayata (Lee, 2010) and Pleione formosana Hayata (Chang and Lee, 1992). In both cases, collecting shoot buds during the cold season significantly improved the survival of explants, shoot formation, and multiplication. The high viability and multiplication of the explant collected during the cold season may reflect the natural course of endogenous metabolism. A study by Lee and Teng (1987) reported the dramatic increase of endogenous gibberellins and indole-3-acetic acid (IAA) levels in $P$. formosana corms after cold storage. Most temperate orchids are deciduous, and their underground organs (e.g., rhizomes and corms) are covered by snow during the winter, whereas Paphiopedilum species are evergreen and inhabit subtropical and tropical areas (Cribb, 1998). However, in the natural habitat, such as the subtropical monsoon climate region or a high-altitude area, Paphiopedilum plants still experience noticeable changes of temperature and rainfall yearly (Averyanov et al., 2003). In this study, it seems that the season-dependent metabolites, such as plant hormones, are retained in the explants under the in vitro
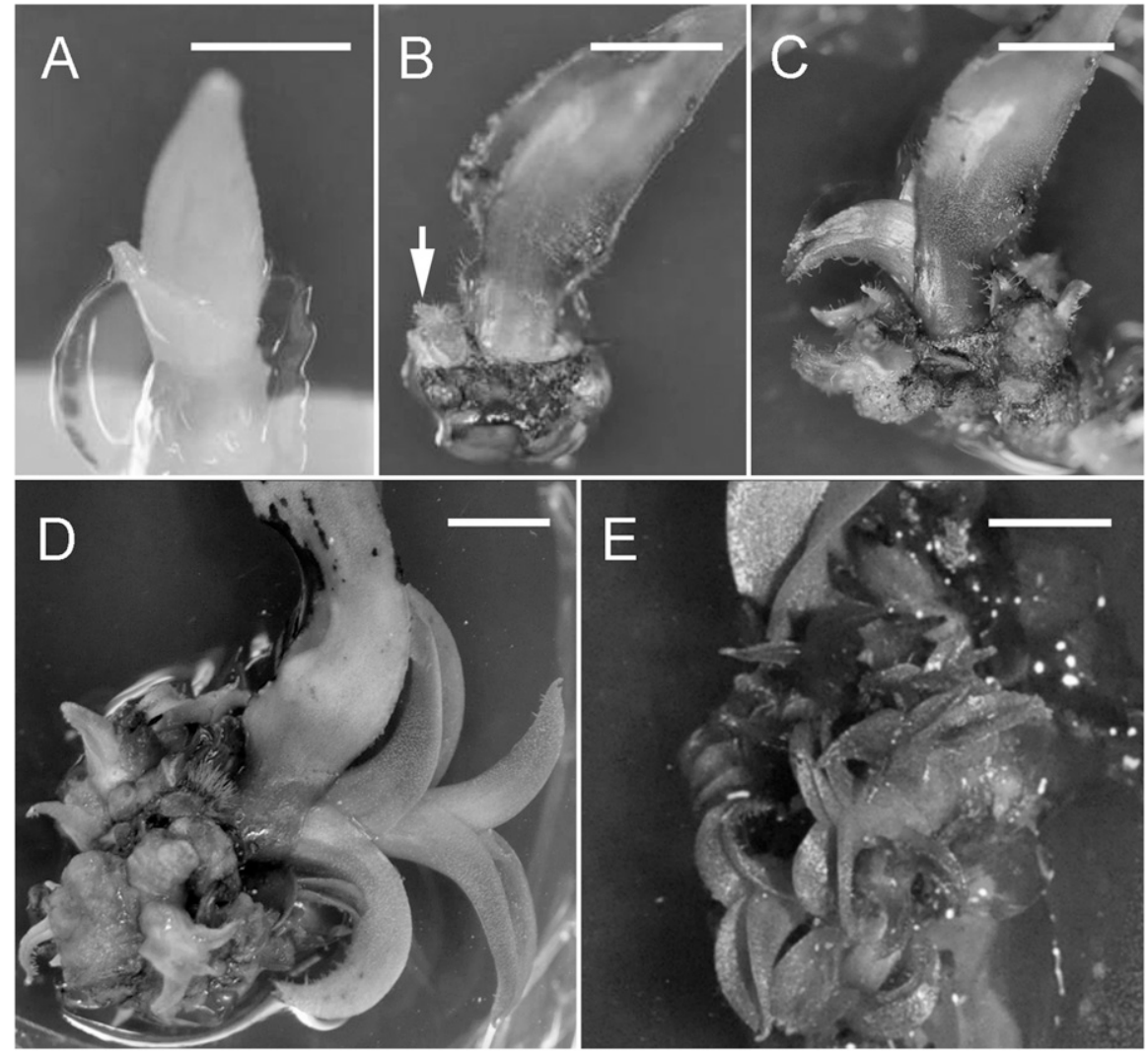

Fig. 2. Micropropagation of Paphiopedilum 'Hsinying Maudiae Leopard'. (A) After the surface sterilization, the lateral bud with one leaf attached was used as the explant. Bar $=1 \mathrm{~cm}$. (B) After 2 months of culture, the basal axillary buds (arrow) started growing. Bar $=1 \mathrm{~cm}$. (C) After 5 months of culture, a number of axillary buds had arisen from the basal part of explants. Bar $=1 \mathrm{~cm}$. (D) The newly formed axillary shoots (as indicated in C) were excised for multiplication. After 3 months of subculture, several new shoots were visible. Bar $=1 \mathrm{~cm}$. (E) The newly formed axillary shoots (as indicated in D) were excised again for multiplication. After 3 months of subculture, more shoot multiplication can be observed. $\mathrm{Bar}=1 \mathrm{~cm}$.

Table 1. Seasonal effects on initial establishment of aseptic culture of two Paphiopedilum hybrids. ${ }^{2}$

\begin{tabular}{llccc}
\hline & & Contamination (\%) & Browning (\%) & Survival (\%) \\
\hline Hybrid & $P$. In-Charm Silver Bell & $24.58 \mathrm{c}^{\mathrm{y}}$ & $4.58 \mathrm{~b}$ & $70.83 \mathrm{a}$ \\
& $P$. Hsinying Maudiae Leopard & $37.5 \mathrm{~b}$ & $7.50 \mathrm{ab}$ & $55.00 \mathrm{~b}$ \\
\multirow{5}{*}{ Season } & & $* * *$ & $*$ & $* * *$ \\
& February & $30.56 \mathrm{~b}$ & 7.22 & $62.22 \mathrm{a}$ \\
& May & $42.78 \mathrm{~b}$ & 4.44 & $61.11 \mathrm{a}$ \\
& August & $43.33 \mathrm{a}$ & 10.00 & $46.67 \mathrm{~b}$ \\
& November & $43.33 \mathrm{a}$ & 7.22 & $50.00 \mathrm{~b}$ \\
Hybrid $\times$ Season & & $* *$ & NS & $* *$ \\
\hline
\end{tabular}

${ }^{\mathrm{z}}$ Data were recorded after 2 months of culture.

${ }^{\mathrm{y}}$ Means having the same letter within a column are not significantly different at $5 \%$ according to least significant difference test.

NS, *,**, ***Nonsignificant or significant at $5 \%, 1 \%$, or $0.1 \%$, respectively.

Table 2. Seasonal effects on shoot formation in two Paphiopedilum hybrids. ${ }^{\mathrm{z}}$

\begin{tabular}{llccc}
\hline & \multicolumn{4}{c}{ Shoot forming (\%) } \\
\cline { 2 - 5 } Hybrid & February & May & August & November \\
\hline$P$. In-Charm Silver Bell & $97.92 \mathrm{aA}^{\mathrm{y}}$ & $97.62 \mathrm{aA}$ & $62.64 \mathrm{aB}$ & $48.33 \mathrm{aC}$ \\
$P$. Hsinying Maudiae Leopard & $80.48 \mathrm{bA}$ & $92.62 \mathrm{aA}$ & $11.57 \mathrm{bB}$ & $10.19 \mathrm{bB}$ \\
Significance of two-way ANOVA & & & & \\
Hybrid & & & $* * *$ & \\
Season & & & $* *$ & \\
Hybrid $\times$ Season & & $* *$ & \\
\hline
\end{tabular}

${ }^{\mathrm{z}}$ Data were recorded after 5 months of culture.

${ }^{\mathrm{y}}$ Means having the same letter within a column (in small letter), and within a row (in capital letter) are not significantly different at $5 \%$ according to least significant difference test.

$* *, * * *$ Significant at $1 \%$ or $0.1 \%$, respectively.

ANOVA $=$ analysis of variance. 
Table 3. Seasonal effects on shoot multiplication in two Paphiopedilum hybrids. ${ }^{\text {z }}$

\begin{tabular}{llccc}
\hline & \multicolumn{3}{c}{ Shoot multiplication (number of new shoots/explant) } \\
\cline { 2 - 5 } Hybrid & February & May & August & November \\
\hline$P$. In-Charm Silver Bell & $6.32 \mathrm{aA}^{\mathrm{y}}$ & $3.80 \mathrm{aB}$ & $1.15 \mathrm{aC}$ & $0.92 \mathrm{aC}$ \\
$P$. Hsinying Maudiae Leopard & $4.68 \mathrm{bA}$ & $4.50 \mathrm{aA}$ & $0.90 \mathrm{bB}$ & $0.50 \mathrm{bB}$ \\
Significance of two-way ANOVA & & & $* * *$ & \\
Hybrid & & & $* * *$ \\
Season & & & $* * *$ \\
Hybrid $\times$ Season & & & \\
\hline
\end{tabular}

${ }^{\mathrm{z}}$ Data were recorded after 8 months of culture and shoots were counted if reaching $0.2 \mathrm{~cm}$ in height.

${ }^{\mathrm{y}}$ Means having the same letter within a column (in small letter), and within a row (in capital letter) are not significantly different at $5 \%$ according to least significant difference test.

$* * *$ Significant at $0.1 \%$.

ANOVA $=$ analysis of variance.

Table 4. Effects of transcinnamic acid (tCA) on shoot multiplication of Paphiopedilum In-Charm Silver Bell. ${ }^{z}$

\begin{tabular}{lccc}
\hline Treatments & Shoot $>1 \mathrm{~cm}$ & Shoot $<1 \mathrm{~cm}$ & Total shoot number \\
\hline Control & $1.33 \pm 0.19 \mathrm{~b}$ & $0.67 \pm 0.19 \mathrm{~b}$ & $2.00 \pm 0.19 \mathrm{~b}$ \\
1 mo cultured with tCA & $2.67 \pm 0.51 \mathrm{a}^{\mathrm{y}}$ & $3.78 \pm 0.48 \mathrm{a}$ & $6.44 \pm 0.91 \mathrm{a}$ \\
& $*$ & $* *$ & $* *$ \\
\hline
\end{tabular}

${ }^{\mathrm{z}}$ The lateral shoot buds were collected in November, and data were recorded after 8 months of culture.

${ }^{\mathrm{y}}$ Mean \pm SE. Means having the same letter within a column (are not significantly different at $5 \%$ according to least significant difference test).

*, **Significant at $0.5 \%$ or $0.1 \%$, respectively.
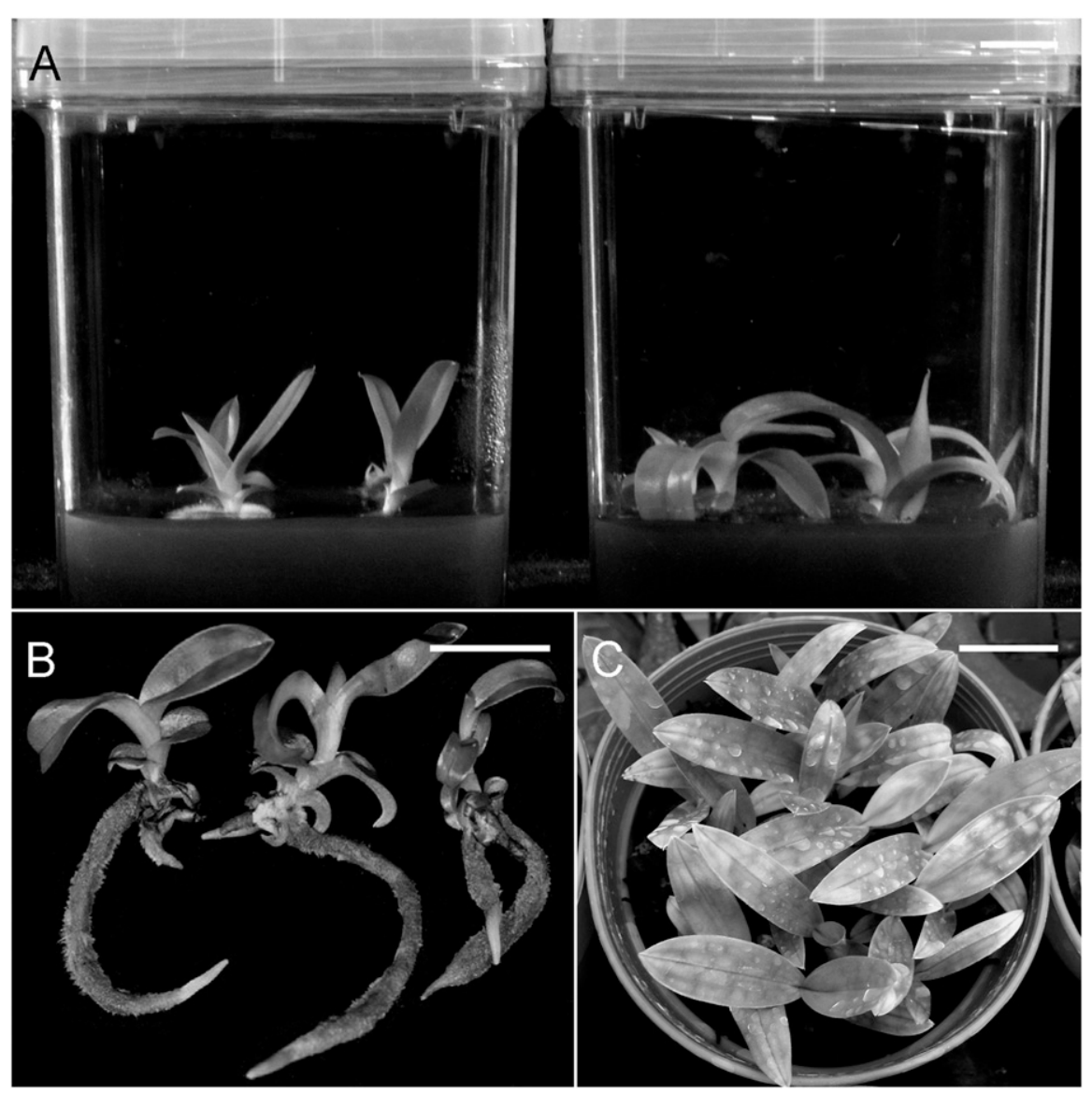

Fig. 3. Rooting and acclimatization of plantlets. (A) Shoots were excised and cultured on the rooting medium in the Magenta GA-7 plant culture box. Bar $=1 \mathrm{~cm}$. (B) After 4 months of culture, plantlets with well-developed roots were ready to take out of flasks. Bar $=2 \mathrm{~cm}$. (C) After 3 months of culture in the greenhouse, the vigorous plantlets with newly emerged leaves could be observed. Bar $=2 \mathrm{~cm}$.

culture condition, and subsequently they affect the growth and multiplication of axillary buds. Further study on the seasonal changes of endogenous hormones of explants

is essential to clarify the role of seasonal influence on aseptic culture establishment.

Effects of $t C A$ on shoot multiplication. In Paphiopedilum micropropagation, the low proliferation rate of axillary shoots may be attributed to the presence of strong apical dominance (Udomdee et al., 2012). Apical dominance is thought to be mediated by IAA (auxin) produced in the apical bud that inhibits axillary bud outgrowth (McSteen and Leyser, 2005; Muller and Leyser, 2011). tCA has been demonstrated as an antiauxin chemical or an inhibitor of polar auxin transport (Liu et al., 1993; Van Overbeek et al., 1951). In the studies on orchid micropropagation, the application of tCA in combination with cytokinins has been shown to increase shoot multiplication in node culture of Dendrobium, and there was no shoot development in the control without tCA (Mosich et al., 1974). In the culture of Phalaenopsis stalk buds, tCA promoted multiple shoot formation by breaking shoot apical dominance (Arditti and Ernst, 1993). In this study, the impact of auxin distribution on lateral bud growth of Paphiopedilum explants was investigated by adding tCA into the culture medium. As compared with the control, the treatment of tCA revealed a significant effect on improving the formation of axillary shoots of Paphiopedilum 'In-Charm Silver Bell' (Table 4). Our results are consistent with previous studies that tCA can interrupt the polar flow of auxin and thus can enhance shoot multiplication of axillary shoots by breaking shoot apical dominance.

Rooting and acclimatization of plantlets. In the multiplication medium, shoots of more than $2 \mathrm{~cm}$ in length were excised and transferred onto the rooting medium (Fig. 3A), and after 4 months of culture, the plantlets with well-developed roots were ready for acclimatization in the greenhouse (Fig. 3B). After taking out of flasks for 3 months, the plantlets were vigorous in the potting mixture with newly emerged leaves (Fig. 3C). In conclusion, we demonstrate an efficient procedure of Paphiopedilum micropropagation for explants collected from adult plants. Collecting the explants in February and May for initial aseptic culture gives optimal survival, shoot formation, and multiplication. The addition of tCA in combination of BA promoted multiple shoot formation by releasing shoot apical dominance. Once the aseptic culture established, the shoots can be multiplied repeatedly. The technique described here makes it possible to propagate the selected elites of Paphiopedilum in quantity for the horticultural market.

\section{Literature Cited}

Arditti, J. and R. Ernst. 1993. Micropropagation of orchids. Wiley, New York.

Averyanov, L., P. Cribb, P.K. Loc, and N.T. Hiep. 2003. Slipper orchids of Vietnam. The Royal Botanic Gardens, Kew, Compass Press Limited.

Chang, Y.C. and N. Lee. 1992. Tissue culture of Pleione formosana Hayata. J. Chinese Soc. Hort. Sci. 38:80-90.

Chen, T.Y., J.T. Chen, and W.C. Chang. 2004. Plant regeneration through direct shoot bud formation from leaf cultures of Paphiopedilum orchids. Plant Cell Tissue Organ Cult. 76:11-15.

Chugh, S., S. Guha, and I.U. Rao. 2009. Micropropagation of orchids: A review on the potential 
of different explants. Scientia Hort. 122:507520.

Cribb, P.J. 1998. The genus Paphiopedilum, 2nd ed. The Royal Botanical Gardens, Natural History Publications, Kew, UK.

Evers, P.W., J. Donkers, A. Prat, and E. Vermeer. 1988. Micropropagation of forest trees through tissue culture. Pudoc, Wageningen, Netherlands.

Hohtola, A. 1988. Seasonal changes in explant viability and contamination of tissue cultures from mature Scots pine. Plant Cell Tissue Organ Cult. 15:211-222.

Hong, P.I., J.T. Chen, and W.C. Chang. 2008. Plant regeneration via protocorm like body formation and shoot multiplication from seed derived callus of a maudiae type slipper orchid. Acta Physiol. Plant. 30:755-759.

Huang, L.C. 1988. A procedure for asexual multiplication of Paphiopedilum in vitro. Am. Orchid Soc. Bull. 57:274-277.

Huang, L.C., C.J. Lin, C.I. Kuo, B.L. Kuang, and T. Murashige. 2001. Paphiopedilum cloning in vitro. Scientia Hort. 91:111-121.

Kartsonas, E. and M. Papafotiou. 2007. Mother plant age and seasonal influence on in vitro propagation of Quercus euboica Pap., an endemic, rare and endangered oak species of Greece. Plant Cell Tissue Organ Cult. 90:111-116.

Kumar, R., K. Sharma, and V. Agrawal. 2005. In vitro clonal propagation of Holarrhena antidysenterica (L.) Wall. through nodal explants from mature trees. In Vitro Cell. Dev. Biol. Plant 41:137-144.

Lee, Y.I. 2010. Micropropagation of Cypripedium formosanum Hayata through axillary buds from mature plants. HortScience 45:1369-1372.

Lee, Y.I. 2018. Vegetative propagation of orchids, p. 403-426. In: Y.I. Lee and E.C. Yeung (eds.).
Orchid propagation: From laboratories to greenhouses - methods and protocols. Springer Protocols Handbooks. Humana Press, New York, NY.

Lee, N. and W.L. Teng. 1987. Endogenous growth promoter and inhibitor levels in Pleione formosana corms. Acta Hort. 205:225-231.

Liao, Y.J., Y.C. Tsai, Y.W. Sun, R.S. Lin, and F.S. Wu. 2011. In vitro shoot induction and plant regeneration from flower buds in Paphiopedilum orchids. In Vitro Cell. Dev. Biol. Plant 47:702-709.

Lin, Y.H., C. Chang, and W.C. Chang. 2000. Plant regeneration from callus culture of a Paphiopedilum hybrid. Plant Cell Tissue Organ Cult. 62:21-25.

Long, B., A.X. Niemiera, Z.Y. Cheng, and C.L. Long. 2010. In vitro propagation of four threatened Paphiopedilum species (Orchidaceae) Plant Cell Tissue Organ Cult. 101:151-162.

Liu, C., Z. Xu, and N.H. Chua. 1993. Auxin polar transport is essential for the establishment of bilateral symmetry during early plant embryogenesis. Plant Cell 5:621-630.

Martini, A.N., M. Papafotiou, and S.N. Vemmos. 2013. Season and explant origin affect phenolic content, browning of explants, and micropropagation of xMalosorbus florentina (Zucc.) Browicz. HortScience 48:102-107.

McSteen, P. and O. Leyser. 2005. Shoot branching. Annu. Rev. Plant Biol. 56:353-374.

Miguel, T.P., W.S. Sakai, and J. Fang. 2010. Gibberellic acid induced flowering of Paphiopedilum (Macabre $\times$ glanduliferum). Acta Hort. 766:279-282.

Mosich, S.K., E.A. Ball, and J. Arditti. 1974. Clonal propagation of Dendrobium by means of node culture. Am. Orchid Soc. Bull. 43:1055-1061.
Muller, D. and O. Leyser. 2011. Auxin, cytokinin and the control of shoot branching. Ann. Bot. 107:1203-1212.

Murashige, T. and F. Skoog. 1962. A revised medium for rapid growth and bioassays with tobacco tissue cultures. Physiol. Plant. 15:473479.

Ng, C.Y. and N.M. Saleh. 2011. In vitro propagation of Paphiopedilum orchid through formation of protocorm-like bodies. Plant Cell Tissue Organ Cult. 105:193-202.

Ng, C.Y., N.M. Saleh, and F.Q. Zaman. 2010. In vitro multiplication of the rare and endangered slipper orchid, Paphiopedilum rothschildianum (Orchidaceae). Afr. J. Biotechnol. 9:20622068.

Nhut, D.T., D.T.T. Thuy, N.T. Don, V.Q. Luan, N.T. Hai, K.T.T. Van, and C.C. Chinnapp. 2007. In vitro stem elongation of Paphiopedilum delenatii Guillaumin and shoot regeneration via stem node culture. Prop. Ornamental Plants 7:29-36.

Stewart, J. and J. Button. 1975. Tissue culture studies in Paphiopedilum. Amer. Orchid Soc. Bull. 44:591-599.

Thomas, P. and M.B. Ravindra. 1997. Shoot tip culture in mango: Influence of medium, genotype, explant factors, season and decontamination treatments on phenolic exudation, explant survival and axenic culture establishment. J. Hort. Sci. 72:713-722.

Udomdee, W., P.J. Wen, S.W. Chin, and F.C. Chen. 2012. Shoot multiplication of Paphiopedilum orchid through in vitro cutting methods. Afr. J. Biotechnol. 11:14077-14082.

Van Overbeek, J., R. Blondeau, and V. Horne. 1951. Trans-cinnamic acid as an anti-auxin. Amer. J. Bot. 38:589-595. 